\title{
Um salto qualitativo e quantitativo das salas virtuais desenvolvidas no curso Moodle em escola pública de Educação Básica
}

\author{
Adriana Dallacosta ${ }^{1}$, Alice Severo Brum ${ }^{2}$, Kelly Hannel ${ }^{1}$ \\ ${ }^{1}$ Seção de Informática - ${ }^{2}$ Supervisão Escolar - Colégio Militar de Porto Alegre (CMPA) \\ Porto Alegre - RS - Brasil \\ \{adri.dallacosta, alice.rbs, khannel\}@gmail.com
}

\begin{abstract}
This paper presents the theoretical and methodological guidelines that supported the reformulation of the Moodle course for teachers of a public school in Basic Education. The changes implemented provided a significant gain in the number of virtual classrooms opened to students, and especially the quality of them. In order to analyze and validate the methodology applied in the course a survey was conducted to find out what was most meaningful to teachers/students' learning.
\end{abstract}

Resumo. Este artigo apresenta as diretrizes teórico-metodológicas que embasaram a reformulação do curso Moodle para professores de uma escola pública de Educação Básica. As mudanças implementadas proporcionaram um ganho significativo no número de salas abertas para os alunos e, principalmente, na qualidade dessas salas. Com o objetivo de analisar e validar a metodologia aplicada no curso, foi realizada uma pesquisa a fim de descobrir o que foi mais significativo para a aprendizagem dos concludentes.

\section{Introdução}

Não há como negar a necessidade dos professores da Educação Básica apropriarem-se das Tecnologias de Informação e Comunicação (TICs) para atingir e conquistar os educandos que hoje sentam nos bancos escolares. A capacitação desses profissionais se faz urgente e o curso Moodle pode ser um dos caminhos para a aproximação desses públicos, docente e discente, oriundos de épocas e formações tão diferentes e distantes. Pesquisa aponta que ainda há falta de conhecimento das TICs por parte dos professores:

em como usá-las, quando usá-las e quais usar em determinados conteúdos, para que possam ser de fato eficazes e promover um ambiente propício ao desenvolvimento da cognição dos alunos envolvidos (Generoso et al, 2013, p. 238).

Martins e Girafa (2008) lembram que os profissionais da educação, que atuam hoje nas escolas, foram formados via "tecnologia" baseada em comunicação com papel e lápis e, portanto, são especialistas na interação presencial, acostumados a olhar o outro e interagir no mesmo meio físico de forma síncrona. Já quanto à "geração DNA digital" - crianças e adolescentes que frequentam hoje o Ensino Fundamental e Médio -, 
complementam:

\begin{abstract}
Esta geração, rodeada de meios tecnológicos, permeia os espaços experimentando novos processos de aprendizagem, interagindo com simulações, reinventa uma forma de se comunicar com o outro e não utiliza como meio principal o lápis e o papel (Martins e Girafa, 2008, p. 1).
\end{abstract}

Segundo Demo (2002 apud Martins, 2008), o desenvolvimento de novas competências docentes é fator determinante nas práticas de ensino e aprendizagens exitosas, principalmente naquelas que envolvem o uso de tecnologias, tais como a Internet e seus recursos. Assim, profissionais que não tiveram acesso a estes conhecimentos e que, portanto, não desenvolveram essas competências por ocasião da graduação, precisam ser capacitados no local de trabalho.

Nesse sentido, entendemos que a educação a distância (EAD), como suporte ao ensino presencial, surge como um meio de aproximar os contextos do aluno e professor. À medida que possibilita a disponibilização de materiais, a interação e a construção de conhecimentos sem a restrição aos espaços físicos, mas também não exige do professor uma quebra radical de suas concepções, pois ainda dispõe da sala de aula presencial, proporciona uma inserção gradual desse profissional ao mundo tecnológico.

A formação continuada dos professores deste estabelecimento de ensino na área de EAD iniciou-se em 2012 por meio da capacitação de professores para a utilização da plataforma Moodle como apoio às atividades presenciais. Ao longo dessa trajetória, observações, pesquisas e análises - com o objetivo de agregar um maior número de professores conhecedores das funcionalidades do Moodle, aumentar o número de salas de aula virtuais e, além disso, tornando as já existentes cada vez mais interativas indicaram a necessidade de mudanças na metodologia do curso.

Este artigo apresentará as diretrizes teórico-metodológicas que embasaram a reformulação do curso Moodle. Além disso, as razões do grande ganho de produtividade dos docentes que concluíram o curso Moodle Básico no ano de 2014, se comparados com os concludentes do ano de 2013, serão analisadas e confrontadas com os resultados da pesquisa aplicada com o objetivo de verificar, na visão dos concludentes, os fatores que mais influenciaram positivamente no seu aprendizado.

A relevância dessa pesquisa está em mostrar os caminhos para as escolas que almejam proporcionar formação continuada em tecnologias da educação nos seus estabelecimentos. É muito comum os professores até realizarem cursos relacionados a esta temática, mas alguns têm muitas dificuldades com relação a esse assunto. Diniz e Darido concordam com essa situação:

Este formador encontra limitações para incluir as ferramentas tecnológicas no contexto de aprendizagem, que, entre outras, incluem a falta de tratamento destas questões na formação inicial e continuada, projetos específicos, condições estruturais, o currículo, bem como a própria dificuldade em lidar com as tecnologias (Diniz e Darido, 2013, p. 243). 
A metodologia aqui apresentada sinaliza caminhos para a aprendizagem de professores imigrantes digitais. Além disso, as melhorias que foram feitas para o ano de 2014, se aplicadas em qualquer curso de formação continuada sobre TICs, contribuirão para o seu sucesso.

\section{Metodologia/recursos utilizados em 2012 / 2013}

Durante o ano de 2012, tivemos 20 professores capacitados no nível básico e 9 deram continuidade aos estudos concluindo o curso avançado. Pode-se afirmar que esta primeira versão do curso foi facilitada pelo fato de os professores voluntários já conhecerem a plataforma Moodle, suas possibilidades e aplicações. O curso foi conduzido de forma a suprir as dúvidas. Os professores/alunos definiam o que seria tratado na próxima aula à medida que traziam suas necessidades, suas expectativas e a professora do curso ajustava o planejamento de forma a atender os interesses do grupo. Assumia a postura, portanto, de mediadora e articuladora das informações que iriam pautar a rede de relações e construção dos conhecimentos.

No ano de 2013, os professores que realizaram o curso Moodle não conheciam as potencialidades desse ambiente. As aulas foram conduzidas de forma a ensinar, desde o início, como abrir uma sala e incluir as atividades e recursos. Dos 21 professores que realizaram o curso básico, somente 6 (seis) continuaram para a o curso avançado.

Além disso, a avaliação dessa edição do curso mostrou resultados desanimadores: a metade dos alunos que concluiu o Curso Moodle Básico não criou uma sala de aula virtual e a maioria das salas criadas não atingiu a qualidade desejada para um concludente de um curso de nível básico.

A avaliação do ano de 2013 apontava a necessidade de mudar radicalmente a forma de conduzir o curso.

\section{Diretrizes teórico-metodológicas do Curso Moodle 2014}

Segundo Hamze (2008), o caminho educacional que busca compreender o adulto pode ser considerado um método de ensino que se reflete em um somatório de trocas de conhecimentos entre o facilitador do conhecimento e o estudante adulto e suas experiências de vida. Segundo a mesma autora, na educação de adultos torna-se importante construir o currículo em prol das necessidades e dos interesses dos estudantes, trazendo informações que serão aplicadas na prática diária.

A formação continuada, termo que optamos por fazer referência aos processos de formação do educador que já concluiu sua formação inicial e exerce sua profissão, surge como um momento necessário para a atualização dos conhecimentos, para a análise das mudanças e para a atribuição das direções esperadas.

Utilizando os pressupostos da formação continuada e apropriando-se de considerações acerca do desenvolvimento de competências e habilidades por adultos, 
onde a aprendizagem é responsabilidade compartilhada entre professor e aluno, fundamentando-se no "aprender fazendo", foram feitas as seguintes alterações na metodologia do curso para o ano de 2014:

- Professor como mediador da aprendizagem: o professor ajudava nas dificuldades de montagem da sala de aula virtual referente à disciplina do professor/aluno. Para a disciplina de Biologia, por exemplo, era interessante mostrar o recurso "pasta", devido ao grande número de imagens que aquele professor dispunha, mas para outros professores, não era necessário. $\mathrm{O}$ curso foi redirecionando para a necessidade do professor/aluno. Hamze $(2008$, p.2) compartilha dessa abordagem andragógica quando diz que "O papel do educador é facilitar a aprendizagem, enfatizando, nesse procedimento, a bagagem de informação trazida por seus educandos".

- Aprendizagem centrada no aluno: mais perguntas do que ensinamentos. Um questionamento, por exemplo, que foi realizado diversas vezes: "O que o(a) senhor(a) quer na sua sala? Vamos pensar juntos como implementar?" Hamze fala da importância do compartilhamento de conceitos e da motivação no processo da aprendizagem de adultos ao afirmar que "A metodologia de ensino e aprendizagem fundamenta-se em eixos articuladores da motivação e da experiência dos aprendizes adultos. Nesse processo os alunos adultos aprendem compartilhando conceitos" (Hamze, 2008, p.2).

- Aplicabilidade imediata: na aula presencial do curso Moodle, o professor/aluno trabalhava e aprimorava a sala virtual que já tinha por meta ser aberta para a sua turma na $6^{\text {a }}$ aula do curso. Cavalcanti (1999) reafirma o interesse que os adultos manifestam pelos conhecimentos que têm aplicação imediata na sua profissão: "Seus interesses pelo aprendizado se direcionam para o desenvolvimento das habilidades que utiliza no seu papel social, na sua profissão" (Knowles, 1973 apud Cavalcanti, 1999, p. 2).

- Linguagem empregada: ela se aproximou do que está sendo utilizado nos planejamentos curriculares destes profissionais. Foram feitas, por exemplo, analogias do "Rótulo" e do "Título do Box" do Moodle com as Sequências Didáticas e os Objetos de Conhecimento da sua disciplina.

- Busca e desenvolvimento de materiais na forma de Tema de Casa: o aluno do curso era desafiado a procurar endereços da Internet, vídeos, arquivos, textos, nome para rótulos que, na aula presencial, incluiria na sua sala de aula virtual. Dessa maneira, a aula presencial rendia, pois os professores/alunos incluíam tudo aquilo que foi selecionado no seu planejamento realizado em casa. Em outras versões do curso, muito tempo era empreendido na aula presencial buscando materiais na Internet. Essa metodologia vai ao encontro do que Santos et al (2011) apud Generoso et al (2013, p. 232) salienta ao afirmar que a formação do professor deve "superar os cursos de capacitação onde o uso das tecnologias se restringe ao acúmulo de fórmulas ou atividades prontas para o professor, ou seja,'treinamento', desvinculado de seu contexto e realidade". 
Além das alterações descritas acima, foi disponibilizada uma apostila chamada "Moodle Pedagógico e Descomplicado para Professores", recurso didático confeccionado especialmente para o curso. A apostila foi feita utilizando uma linguagem dialógica, próxima do professor e bem distante de termos técnicos. Essa apostila mostra os usos pedagógicos dos recursos e das atividades do Moodle.

Outra alteração ocorreu no momento da formação das turmas, com turmas menores, de dois a sete professores. Sobre essa questão, Calvalcanti (1999) reafirma a importância de facilitar as discussões em pequenos grupos oportunizando a manifestação de suas angústias e dificuldades sem medo de serem ridicularizados.

\section{Método}

Nessa seção, apresentam-se a questão da pesquisa (sua condução), a seleção do método, a etapa exploratória e o instrumento de apoio (questionário).

\subsection{Questão da pesquisa}

Por que os professores do curso Moodle 2014 produziram uma quantidade maior de salas virtuais e com um padrão de qualidade superior se comparado com os de 2013 ?

A fim de possibilitar uma avaliação em termos qualitativos, fez-se necessário criar uma classificação para enquadrar as salas virtuais dos professores/alunos do curso do Moodle. Para tanto, optou-se pela seguinte nomenclatura:

- Padrão C: até 11 recursos adicionados na sala. É a sala virtual que tem o mérito de ter sido aberta, porém um pouco aquém em nível de qualidade.

- Padrão B: de 12 a 24 recursos. É a sala virtual que está dentro dos padrões de qualidade.

- Padrão A: mais de 25 recursos. É a sala virtual que superou as expectativas em termos de qualidade.

Realizando a análise quantitativa do ano de 2013, percebe-se que apenas 48\% dos professores/alunos que realizaram o curso abriram uma sala virtual no Moodle para os seus alunos. Em termos de qualidade, há um predomínio de salas no padrão $\mathrm{C}$ e, das salas criadas, apenas 30\% se encontraram no Padrão A, conforme ilustra o gráfico 1.

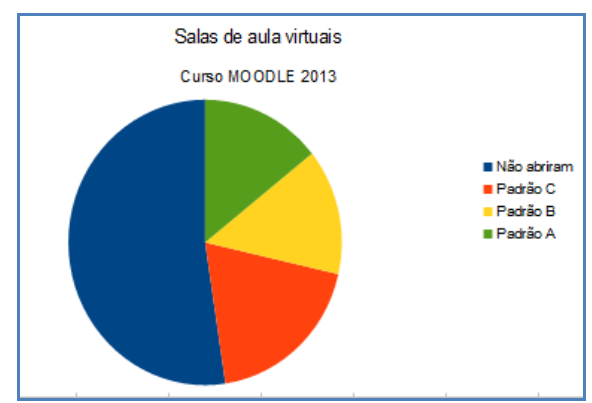

Gráfico 1. Análise qualitativa e quantitativa do Curso Moodle Básico - 2013 
Em 2014 ocorreu um aumento significativo do número de salas abertas. Em termos de qualidade, houve um predomínio de salas no padrão A. Dos professores/alunos que realizaram o curso em 2014, $82 \%$ abriram salas de aula virtual no Moodle e, das salas criadas, $50 \%$ se encontraram no Padrão A.

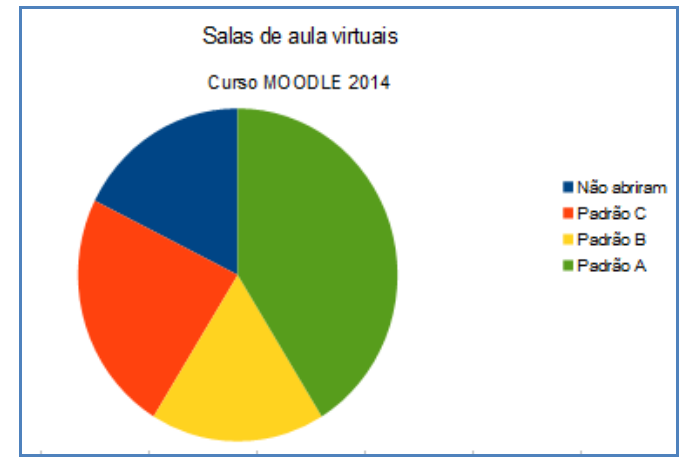

Gráfico 2. Análise qualitativa e quantitativa do Curso Moodle Básico - 2014

Aplicou-se uma pesquisa com os concludentes dos anos de 2013 e 2014 com o objetivo de descobrir o que foi relevante na metodologia implementada para a sua aprendizagem.

\subsection{Seleção do método de pesquisa}

A pesquisa referente a esse artigo classifica-se como pesquisa exploratória assumindo a forma de estudo de campo. A pesquisa exploratória tem como preocupação central "identificar os fatores que determinam ou que contribuem para a ocorrência dos fenômenos. Esse é o tipo de pesquisa que mais aprofunda o conhecimento da realidade, porque explica a razão, o porquê das coisas" (Gil, 2002, p. 42).

Para Neto, o estudo de campo "se apresenta como uma possibilidade de conseguirmos não só uma aproximação com aquilo que desejamos conhecer e estudar, mas também de criar um conhecimento, partindo da realidade presente no campo" (Neto, 1994, p. 51).

O estudo de campo realizado contou com uma etapa exploratória. Gil define esse momento como sendo "um período de investigação informal e relativamente livre, no qual o pesquisador procura obter, tanto quanto possível, entendimento dos fatores que exercem influência na situação que constitui o objeto de pesquisa" (Gil, 2002, p. 130).

\subsection{Etapa exploratória}

Realizou-se uma etapa exploratória com os concludentes do curso dos anos anteriores objetivando identificar os fatores que alavancaram o uso do Moodle nesse Estabelecimento de Ensino. Essa pesquisa foi respondida por todos os professores/alunos que trabalharam com o Moodle em 2012. 
Tabela 1. Fatores que alavancaram o uso do MOODLE na nossa escola

\begin{tabular}{|l|l|}
\hline $\begin{array}{c}\text { No de vezes que a } \\
\text { opção foi marcada }\end{array}$ & \multicolumn{1}{c|}{ Opções } \\
\hline 14 & Cursos de capacitação \\
\hline 12 & $\begin{array}{l}\text { A disponibilidade de um profissional com formação em Informática da } \\
\text { Educação em tempo integral na escola para tirar dúvidas }\end{array}$ \\
\hline 07 & O fato de outros colegas estarem utilizando esse ambiente virtual. \\
\hline 05 & Palestras de motivação \\
\hline 00 & Os alunos solicitarem uma sala de aula virtual. \\
\hline 00 & Outro \\
\hline
\end{tabular}

Os cursos de capacitação oferecidos pelo próprio estabelecimento de ensino e a disponibilidade de ter um profissional em tempo integral na escola para tirar dúvidas e ajudar na implantação de atividades foram, na opinião do público que respondeu ao questionário, as molas propulsoras do projeto.

\subsection{Concepção do instrumento de apoio}

Tabela 2. Questionário para coleta das informações

\begin{tabular}{|l|l|}
\hline \multicolumn{1}{|c|}{ Questão } & \multicolumn{1}{|c|}{ Objetivos da questão } \\
\hline Dados do Entrevistado & $\begin{array}{l}\text { Identificar nome e se foi concludente do } \\
\text { curso Moodle Básico no ano de 2013 ou } \\
2014\end{array}$ \\
\hline $\begin{array}{l}\text { Q1. O que o motivou a conhecer o MOODLE? } \\
\text { Você pode marcar até 3 (três) opções. }\end{array}$ & $\begin{array}{l}\text { Identificar as razões que motivaram o } \\
\text { professor a realizar o Curso Moodle. }\end{array}$ \\
\hline $\begin{array}{l}\text { Q2. O que foi relevante para o seu aprendizado? } \\
\text { Numere de acordo com a ordem de prioridade OU } \\
\text { assinale a última opção indicando o que faltou. }\end{array}$ & $\begin{array}{l}\text { Identificar o que o professor considera } \\
\text { de mais importante no curso para } \\
\text { facilitar a aprendizagem do Moodle. }\end{array}$ \\
\hline $\begin{array}{l}\text { Q3. O que foi fator determinante para a abertura da } \\
\text { sala virtual? Você pode marcar mais de uma opção } \\
\text { OU assinalar a última opção "não abri uma sala". }\end{array}$ & $\begin{array}{l}\text { Identificar o que levou o professor a } \\
\text { abrir a uma sala de aula virtual para os } \\
\text { seus alunos. }\end{array}$ \\
\hline $\begin{array}{l}\text { Q4. Quais contribuições, direta ou indiretamente, o } \\
\text { curso oportuniza? Você pode marcar até 3 (três) } \\
\text { opções. }\end{array}$ & $\begin{array}{l}\text { Identificar o retorno que o curso } \\
\text { proporciona para a prática pedagógica } \\
\text { do professor. }\end{array}$ \\
\hline Q5. Espaço para registro de outras observações. & $\begin{array}{l}\text { Local para o professor expressar aquilo } \\
\text { que ele deseja sobre o Moodle ou sobre } \\
\text { o curso. }\end{array}$ \\
\hline
\end{tabular}

\subsection{Condução da pesquisa}

A condução da pesquisa se deu em dois momentos: um olhar do profissional que ministra o curso contabilizando e classificando as salas nos padrões definidos na seção 
4.1 e, num segundo momento, por meio de um questionário, a análise das respostas dos concludentes.

O questionário foi distribuído para os concludentes dos cursos de 2013 e 2014. Retornaram preenchidos 6 (seis) questionários da turma de 2013 e 09 (nove) de 2014.

\section{Resultados e discussões}

Na questão 1, sobre os motivos que levaram os professores a realizarem o curso Moodle, foram os seguintes itens escolhidos por ordem de prioridade:

$1^{\mathrm{o}}$ - vontade de incluir as novas tecnologias na sua prática pedagógica;

$2^{\circ}$ - necessidade de capacitação pessoal para acompanhar a evolução tecnológica;

$3^{\circ}$ - oportunidade de fazer um curso gratuito, no local e horário de trabalho;

$4^{\mathrm{o}}$ - possibilidade de aplicabilidade imediata.

Na questão 2, ao enumerar em ordem de prioridade o que foi mais relevante para o seu aprendizado no curso, tanto os professores/alunos que realizaram o curso no ano de 2013, quanto os de 2014, escolheram como primeira opção a "Postura cooperativa e mediadora do profissional que ministra o curso com sugestões de melhoria e ajuda individualizada. A ação ensino-aprendizagem centrada no aluno por meio da seleção de materiais, artigos, imagens e vídeos voltados ao interesse/necessidade do professor/aluno".

Como segunda opção para essa mesma questão, tanto os concludentes do ano de 2013, quanto os de 2014, elegeram a alternativa: "Construção da sala virtual durante as aulas, possibilitada por meio da busca de arquivos/conteúdos pesquisados em casa (tema de casa) que eram incorporados ao Moodle na aula presencial”.

Ressalta-se que, para os concludentes de 2014, a segunda opção ficou equiparada à outra alternativa: "Ter realizado o curso numa turma pequena, de 3 a 5 alunos".

Na questão 3, visando investigar o fator determinante para a abertura da sala de aula virtual pelo professor, a opção que mais apareceu foi a construção de uma sala virtual "real" que, num curso espaço de tempo, poderá servir de apoio à sua disciplina e aos seus alunos, ou seja, construída a partir da terceira aula do curso, com possibilidade de aplicação imediata.

A segunda opção mais selecionada para a questão 4 foi "A inclusão, durante as aulas presenciais, de recursos referentes à disciplina que ministra, em vez arquivos descontextualizados da sua prática".

$\mathrm{Na}$ questão 4, sobre as contribuições que o curso oportuniza, os professores escolheram em ordem de prioridade: disponibilizar o conteúdo de sua disciplina para acesso em casa; melhorar a sua prática pedagógica; despertar o interesse dos alunos pela sua disciplina e elaborar aulas mais interessantes. 
As respostas da única pergunta aberta da pesquisa foram agrupadas na categoria "formação continuada". Vários professores agradeceram espontaneamente a oferta do curso pela escola e solicitaram outros cursos nessa área.

É relevante também o depoimento de um professor que realizou o curso em 2013 e o repetiu em 2014. Perguntamos, por e-mail, sobre as diferenças do curso e ele escreveu que no ano de 2014 obteve um rendimento maior devido ao número reduzido de professores/alunos em sala, a linguagem empregada e a disponibilização da apostila.

\section{Conclusão}

A formação continuada do Moodle tem como objetivo ir além do aprendizado dos professores/alunos. Busca-se também qualidade no produto final do curso: a sala de aula virtual da sua disciplina. $O$ ano de 2014 marcou um grande avanço: 82\% dos professores abriram suas salas de aula virtuais no Moodle e, das salas criadas, 50\% atingiram o Padrão A (conceito excelente).

Esse resultado deve ainda ser mais evidenciado, pois dos únicos 3 (três) professores/alunos que não abriram a sala no ano de 2014, 2 (dois) não utilizam o computador para as atividades diárias (não possuindo os conhecimentos básicos de Informática). Esse dado foi um aprendizado, pois indicou que são necessários prérequisitos para se matricular nesse tipo de curso. No próximo semestre, será ofertado o curso "Busca e desenvolvimento de materiais para o Moodle" para contemplar estes usuários.

É interessante ressaltar que o "movimento Moodle" na escola tomou proporções não esperadas. Professores, até então totalmente avessos às tecnologias, procuraram a capacitação ofertada. Esse ambiente pode ser considerado de inclusão digital, pois os únicos profissionais que não estavam incluídos digitalmente se motivaram a ingressar no mundo das TICs utilizando o curso do Moodle como suporte.

A etapa exploratória e a nossa percepção apontam que a postura e a formação do profissional que ministra o curso é de extrema relevância. É muito importante que ele tenha uma formação em Informática e na área da Educação. Como apresentar formas de implementar atividades pedagógicas para os professores/alunos no Moodle se faltam conhecimentos em Informática ou pedagógicos? O professor deve dominar os dois campos de conhecimento, além de ser entusiasta e paciente.

Outro fator de extrema importância é ter o profissional ministrante do curso à disposição na Escola para sanar as dúvidas dos professores/alunos, pois quando necessitam acrescentar algo novo na sua sala de aula virtual ou quando encontram alguma dificuldade, têm a quem recorrer.

No olhar dos profissionais da amostragem, a utilização do tempo presencial para a construção da sala virtual, a partir da terceira aula do curso, com possibilidade de aplicação imediata do conhecimento, melhorando a sua prática pedagógica, é um fator determinante para o empenho na conclusão do curso. 
Além disso, uma turma pequena é fundamental para o sucesso da formação, pois as interações ocorrerão com mais frequência e com maior qualidade. No ano de 2013, a turma era composta de 12 professores/alunos e ocorria, em média, uma interação por aluno no período da aula presencial. No ano de 2014, como predominaram turmas de três alunos, as interações foram maiores e mais intensas: umas 10 por aula para cada professor/aluno, trocas estas direcionadas para o interesse do professor e que eram revertidas imediatamente em alguma melhoria na sua sala de aula virtual.

Conclui-se, portando, que o mais importante para o processo ensinoaprendizagem do Moodle pelo professor/aluno é a postura cooperativa e mediadora do profissional que ministra o curso com sugestões de melhoria e ajuda individualizada, incentivando, assim, os professores/alunos a conhecerem o ambiente virtual, com tranquilidade e serenidade, o que tornou a aprendizagem mais acessível.

\section{Referências}

Cavalcanti, R. A. (1999) “Andragogia: A aprendizagem nos adultos”. Rev. De Clínica Cirúrgica da Paraíba, n.6, Ano 4, Jul. 1999. Disponível em

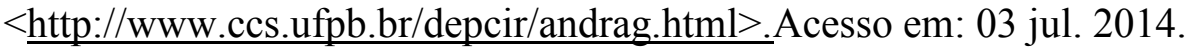

Diniz, I. K. S.; Darido, S. C. (2013) "Explorando as TIC na formação inicial de professores de Educação Física: uma experiência com danças folclóricas". In: Anais do Workshop de Informática na Escola. Disponível em: <http://www.brie.org/pub/index.php/wie/article/view/2602>. Acesso em: 03 jul. 2014.

Generoso, A. A. P.; Neto, C. N.; Reinehr, S.; Malucelli, A. (2013) “Abordagem Qualitativa do uso das TDIC na Educação Básica". In: Anais do Workshop de Informática na Escola. Disponível em: <http://www.brie.org/pub/index.php/wie/article/view/2600>. Acesso em: 03 jul. 2014.

Gil, A. C. (2002) “Como elaborar projetos de pesquisa”. 4.ed. São Paulo: Editora Atlas.

Hamze, A. (2008) "Andragogia e a arte de ensinar aos adultos". Disponível em $<$ http://www.educador.brasilescola.com/trabalho-docente/andragogia.html $>$. Acesso em: 03 jul. 2014.

Martins, C. A.; Giraffa, L. M. M. (2008) "Formação do docente imigrante digital para atuar com nativos digitais no Ensino Fundamental". Disponível em: $<$ http://web02.pucpr.br/eventos/educere/educere2008/anais/pdf/132_220.pdf $>$. Acesso em: 03 jul. 2014.

(2008) "Metodologia de Projetos via MOODLE: uma investigação acerca das competências necessárias aos docentes do Ensino Fundamental". In: Anais do Workshop de Informática na Escola. Disponível em: <http://www.brie.org/pub/index.php/wie/article/view/1014>. Acesso em: 03 jul. 2014.

Neto, O. C. (1994) "O trabalho de campo como descoberta e criação”. In: Pesquisa Social: teoria, método e criatividade. Deslandes, S.; Neto, O. C.; Gomes, R.; Minayo, M. C. S. (org.). Petrópolis, RJ: Vozes. 